\title{
Adipose-Derived Stem Cells Ameliorate Allergic Airway Inflammation by Inducing Regulatory $T$ Cells in a Mouse Model of Asthma
}

\author{
Kyu-Sup Cho, ${ }^{1}$ Mi-Kyung Park, ${ }^{2}$ Shin-Ae Kang, ${ }^{2}$ Hee-Young Park, ${ }^{1}$ Sung-Lyong Hong, \\ Hye-Kyung Park, ${ }^{3}$ Hak-Sun Yu, ${ }^{2}$ and Hwan-Jung Roh ${ }^{4}$ \\ ${ }^{1}$ Department of Otorhinolaryngology and Biomedical Research Institute, Pusan National University Hospital, \\ Busan 602-739, Republic of Korea \\ ${ }^{2}$ Department of Parasitology, Pusan National University School of Medicine, Yangsan 626-870, Republic of Korea \\ ${ }^{3}$ Department of Internal Medicine, Pusan National University Hospital, Busan 602-739, Republic of Korea \\ ${ }^{4}$ Department of Otorhinolaryngology and Research Institute for Convergence of Biomedical Science and Technology, \\ Pusan National University Yangsan Hospital, Beom-eo li, Mul-geum eup, Yang-san si, Gyeongsangnam-do, \\ Yangsan 626-770, Republic of Korea
}

Correspondence should be addressed to Hwan-Jung Roh; rohhj@pusan.ac.kr

Received 18 April 2014; Revised 3 July 2014; Accepted 10 July 2014; Published 26 August 2014

Academic Editor: Alex Kleinjan

Copyright (C) $2014 \mathrm{Kyu}$-Sup Cho et al. This is an open access article distributed under the Creative Commons Attribution License, which permits unrestricted use, distribution, and reproduction in any medium, provided the original work is properly cited.

\begin{abstract}
Although several studies have demonstrated that mesenchymal stem cells derived from adipose tissue (ASCs) can ameliorate allergic airway inflammation, the immunomodulatory mechanism of ASCs remains unclear. In this study, we investigated whether regulatory $\mathrm{T}$ cells (Tregs) induction is a potential mechanism in immunomodulatory effects of ASCs on allergic airway disease and how these induced Tregs orchestrate allergic inflammation. Intravenous administration of ASCs significantly reduced allergic symptoms and inhibited eosinophilic inflammation. Airway hyperresponsiveness, total immune cell and eosinophils in the bronchoalveolar lavage fluid, mucus production, and serum allergen-specific IgE and IgG1 were significantly reduced after ASCs administration. ASCs significantly inhibited Th2 cytokines (IL-4, IL-5, and IL-13) and enhanced Th1 cytokine (IFN- $\gamma$ ) and regulatory cytokines (IL-10 and TGF- $\beta$ ) in the bronchoalveolar lavage fluid and lung draining lymph nodes. Furthermore, levels of IDO, TGF- $\beta$, and PGE $_{2}$ were significantly increased after ASCs administration. Interestingly, this upregulation was accompanied by increased Treg populations. In conclusion, ASCs ameliorated allergic airway inflammation and improved lung function through the induction of Treg expansion. The induction of Treg by ASCs involves the secretion of soluble factors such as IDO, TGF- $\beta$, and $\mathrm{PGE}_{2}$ and Treg might be involved in the downregulation of Th2 cytokines and upregulation of Th1 cytokines production.
\end{abstract}

\section{Introduction}

Allergic rhinitis (AR) and asthma are chronic, reversible allergic airway diseases that have become a significant global public health concern [1]. Allergic airway diseases are characterized by Th2-skewed eosinophilic inflammation, mucus hypersecretion, and airway hyperresponsiveness (AHR) [1, 2]. The excessive activation of Th2 cells is thought to play a major role in allergic immune reaction, initiating and propagating inflammation through release of a number of Th2 cytokines, such as IL-4 and IL-13, that regulate isotype switching to allergen-specific IgE or IL-5, which recruits and activates eosinophils [3].

Mesenchymal stem cells (MSCs) represent an important stem cell population with multipotent capabilities which may have high utility for translational clinical applications. MSCs were initially isolated from bone marrow (BM) but are now shown to reside in almost adult organ and tissues [4]. Because of their capacity for differentiation, MSCs have emerged as a promising source for therapeutic applications in tissue engineering and regenerative medicine $[5,6]$. In addition to their multilineage potential, MSCs derived from 
adipose tissue (ASCs) may share with other MSCs the unique ability to suppress immune responses and modulate inflammation [7]. MSCs can inhibit natural killer cell function $[8,9]$, modulate dendritic cell maturation $[10]$, and suppress the allogeneic $\mathrm{T}$ cell response [8] by altering the cytokine secretion profile of dendritic cells and $\mathrm{T}$ cells induced by an allogeneic immune reaction. Although the ability of MSCs to modulate immune systems has led to increasing interest in using MSCs as a potential therapeutic modality for allergic airway diseases, only several studies demonstrated MSCs can ameliorate allergic airway inflammatory diseases, including asthma [11-13] and AR [14-17]. Moreover, the immunomodulatory mechanism of MSCs in allergic airway disease is not completely understood.

In this study, we evaluated the effects of MSCs on allergic inflammation, changes of regulatory $\mathrm{T}$ cells (Tregs), and cytokines in ovalbumin (OVA) induced asthmatic mouse model. Furthermore, we investigated whether Tregs induction is a potential mechanism in immunomodulatory effects of MSCs on allergic airway disease and how these induced Tregs orchestrate allergic inflammation.

\section{Materials and Methods}

2.1. Animals. Five-week-old female C57BL/6 mice were purchased from Samtako Co. (Osan, Republic of Korea, http://www.samtako.com.ipaddress.com/) and bred in a specific pathogen free animal facility. The animal study protocol was approved by the Institutional Animal Care and Use Committee of the Pusan National University School of Medicine.

2.2. Isolation and Culture of ASCs. Among MSCs, ASCs were used because of their abundance, relatively easy harvesting, and high proliferation potential. Adipose tissue was obtained from the abdominal fat of C57BL/6 mice. To isolate homogenous ASCs, adipose tissue was washed extensively with equal volumes of phosphate-buffered saline (PBS) and digested with $0.075 \%$ collagenase type I (Sigma, St. Louis, MO) at $37^{\circ} \mathrm{C}$ for 30 minutes. Enzyme activity was neutralized with $\alpha$-modified Eagle's medium ( $\alpha$-MEM) containing $10 \%$ fetal bovine serum (FBS) and the sample was centrifuged at $1,200 \times \mathrm{g}$ for 10 minutes to obtain a pellet. The pellet was filtered through a $100 \mu \mathrm{m}$ nylon mesh to remove cellular debris and incubated overnight at $37^{\circ} \mathrm{C}$ in $5 \% \mathrm{CO}_{2}$ in control medium ( $\alpha$-MEM, 10\% FBS, 100 unit/mL penicillin, $100 \mu \mathrm{g} / \mathrm{mL}$ streptomycin). Following incubation, the plates were washed extensively with PBS to remove residual nonadherent red blood cells. The resulting cell population was maintained at $37^{\circ} \mathrm{C}$ in $5 \% \mathrm{CO}_{2}$ in control medium. One week later, when the monolayer of adherent cells had reached confluence, cells were trypsinized (0.05\% trypsinEDTA; Sigma), resuspended in $\alpha$-MEM containing $10 \% \mathrm{FBS}$, and subcultured at the concentration of $2,000 \mathrm{cells} / \mathrm{cm}^{3}$. For the experiments, we used the third or fourth passage of ASCs.

Flow cytometric analysis was used to characterize the phenotypes of the ASCs. At least 50,000 cells (in $100 \mu \mathrm{L}$ PBS, $0.5 \%$ bovine serum albumin (BSA), $2 \mathrm{mmol} / \mathrm{l}$ EDTA) were incubated with fluorescein isothiocyanate-labeled monoclonal antibodies against mouse stem cell antigen-1 (Sca1), CD44, CD90, CD45, CD 117, and CD11b (BD Biosciences Clontech, Palo Alto, CA) or with the respective isotype control. After washing, labeled cells were analyzed by flow cytometry using FACSCalibur flow cytometer and the Cell Quest Pro software (BD Biosciences, San Diego, CA).

2.3. Mouse Model of Allergic Airways Inflammation. A mouse model of allergic airways inflammation was induced as previously reported with minor modification [18]. Briefly, mice were sensitized by intraperitoneal injection of $75 \mu \mathrm{g}$ of OVA (Sigma, St. Louis, MO, http://www.sigmaaldrich.com) in $2 \mathrm{mg}$ of aluminum hydroxide (Sigma) in $200 \mu \mathrm{L}$ PBS on days $0,1,7$, and 8 . On days 14, 15, 21, and 22 after the initial sensitization, the mice were challenged intranasally with $50 \mu \mathrm{g}$ of OVA in $50 \mu \mathrm{L}$ PBS (Figure 1(a)).

2.4. Intravenous Transplantation of ASCs. ASCs were washed with PBS and suspended in PBS at a concentration of $1 \times 10^{7}$ cells $/ \mathrm{mL}$. To evaluate the effect of ASCs, $0.1 \mathrm{~mL}$ of purified stem cells was injected with a 26-gauge needle via the mouse tail vein once a day on days 12, 13, 19, and 20 (Figure 1(a)).

Mice were divided into four groups, with five mice in each group: (a) PBS group mice were sensitized, pretreated, and challenged with PBS; (b) PBS+ASC group mice were sensitized and challenged with PBS but pretreated with ASCs; (c) OVA group mice were sensitized with OVA, pretreated with PBS, and then challenged with OVA; (d) OVA+ASC group mice were sensitized with OVA, pretreated with ASCs, and then challenged with OVA (Figure 1(b)). These experiments were performed four times according to the same protocol.

2.5. Evaluation of Nasal Symptoms. The frequency of sneezing and nasal rubbing that occurred in the 10-minute time period after the last OVA challenge was determined in a blind manner by two observers.

2.6. Measurement of Methacholine AHR. Twenty-four hours after the last challenge, the AHR was assessed in conscious, unrestrained mice using noninvasive whole-body plethysmography (Allmedicus, Seoul, Republic of Korea) as previously described [19]. In brief, the mice were placed in the plethysmography chamber and exposed to increasing concentrations of aerosolized methacholine at $0,12.5,25$, and $50 \mathrm{mg} / \mathrm{mL}$ for $10 \mathrm{~min}$. The enhanced pause (Penh) was calculated automatically based on the mean pressure generated in the plethysmography chamber during inspiration and expiration combined with the time of each phase. The Penh values calculated during each 3-minute interval were then averaged.

\subsection{Differential Cell Counting in Bronchoalveolar Lavage Fluid.} To obtain bronchoalveolar lavage fluid (BALF), the tracheas of the anesthetized mice were exposed and cut just below the larynx. A polyurethane flexible tube $(0.4 \mathrm{~mm}$ in outer diameter, $4 \mathrm{~cm}$ in length, and attached to a blunt 24-gauge needle (Boin Medical Co., Seoul, Republic of Korea)) was 


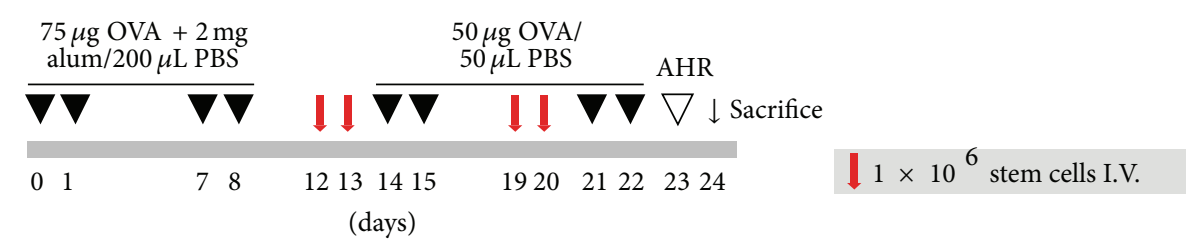

(a)

Five-week-old female C57BL/6 mice

\begin{tabular}{|c|c|c|c|c|}
\hline Group & Sensitization & Challenge & $\mathrm{Tx}^{*}$ & ${ }^{*}$ ASCs I.V. injection \\
\hline PBS & PBS & PBS & - & \\
\hline $\mathrm{PBS}+\mathrm{ASC}$ & PBS & PBS & $\mathrm{O}$ & \\
\hline OVA & OVA & OVA & - & \\
\hline $\mathrm{OVA}+\mathrm{ASC}$ & OVA & OVA & $\mathrm{O}$ & \\
\hline
\end{tabular}

(b)

FIGURE 1: The experimental protocol and group. (a) The mice were sensitized on days $0,1,7$, and 8 by intraperitoneal injection of OVA and challenged intranasally on days $14,15,21$, and $22.1 \times 10^{6}$ purified ASCs were injected via the tail vein on days $12,13,19$, and 20 . (b) The mice were divided into four different groups in accordance with the different sensitization, challenge, and injection.

placed into the trachea, after which the lung was lavaged once with the $800 \mathrm{~mL}$ of sterile warm PBS. The BALF samples were centrifuged for $5 \mathrm{~min}$ at $1,500 \mathrm{rpm}$ at $4^{\circ} \mathrm{C}$. The supernatants were then decanted and immediately frozen at $-70^{\circ} \mathrm{C}$. Cell pellets were resuspended and washed twice in PBS. The total cell numbers were counted using a hematocytometer. BALF cell smears were prepared using cytospin apparatus and stained with Diff-Quik solution (Sysmex Co., Kobe, Japan) to determine the differential cells counts in accordance with conventional morphological criteria. At least 500 cells per slide were evaluated in order to obtain the differential leukocyte counts.

2.8. Lung Histology and Inflammation Scoring. Lung tissues were removed after the lavage, fixed in 10\% neutral formalin for 36 hours, and embedded in paraffin. The thin sections of the embedding tissues were stained with hematoxylin and eosin (H\&E) and periodic acid-Schiff (PAS) for the identification of eosinophils and counting mucin-secreting cells, respectively. Lung inflammation was assessed by the degree of peribronchial and perivascular inflammation, which were evaluated on a subjective scale of $0-4$ as previously described $[20,21]$. The values were given according to the following inflammatory parameters: 0 when no inflammation was detectable, 1 was for occasional cuffing with inflammatory cells, 2 when most bronchi or vessels were surrounded by the depth of one to three cells, 3 when most bronchi or vessels were surrounded by the depth of four to five cells, and 4 when most bronchi or vessels were surrounded by the depth of more than five cells. For quantifying the goblet cell hyperplasia, the percentage of PAS-positive cells in epithelial areas was examined from 8 to 10 tissue sections per mouse.

2.9. Quantitative Real-Time PCR for IDO and TGF- $\beta$. RNA was extracted from the lung by using $1 \mathrm{~mL}$ of QIAzol (Qiagen science, Valencia, CA) and RNA extraction was conducted in accordance with the manufacturer's protocols, transcribing
$2 \mu \mathrm{g}$ of RNA using moloney murine leukemia virus (M-MLV) reverse transcriptase (Promega, Madison, WI). Indoleamine 2,3-dioxygenase (IDO) (forward, 5'-GATGAAGAAGTGGGCTTTGC- $3^{\prime}$; reverse, $5^{\prime}$-TCCAGTTTGCCAAGACACAG- $3^{\prime}$ ) and TGF- $\beta$ (forward, $5^{\prime}$-CTACCTTTCCTTGGGAGACC- $3^{\prime}$; reverse, 5'-CGGGAGTGGGAGCAGAA- $3^{\prime}$ ) RNA levels were quantified, relative to housekeeping gene, GAPDH, using iCycler (Bio-Rad laboratories Inc., Hercules, CA) real-time PCR machines following manufacturer's instructions. The relative expression of the gene was then calculated as the ratio to a housekeeping gene using the genex program (Bio-Rad laboratories Inc.).

2.10. Measurement of Serum Immunoglobulin and $P G E_{2}$. At 48 hours after last OVA challenge, serum was collected from mice via cardiac puncture. Total and OVAspecific immunoglobulins (Ig E, IgG1, and IgG2a) and $\mathrm{PGE}_{2}$ were determined by enzyme-linked immunosorbent assay (ELISA). All of these were conducted in accordance with the manufacturer's instructions (R\&D Systems, Minneapolis, $\mathrm{MN})$. Absorbance $(450 \mathrm{~nm})$ was measured with an ELISA plate reader (Molecular Devices, Sunnyvale, CA).

\subsection{Expression of Cytokines in the BALF and Lung Draining} Lymph Nodes. The concentration of mouse IL-4, IL-5, IL-10, IL-13, interferon- (IFN-) $\gamma$, and transforming growth factor(TGF-) $\beta$ expression in the BALF and in the stimulated supernatants of lung draining lymph nodes (LLNs) was examined using commercially available ELISA kits in accordance with the manufacturer's instructions (eBioscience, San Diego, CA). The absorbance of the final reactant was determined at $450 \mathrm{~nm}$ with an ELISA plate reader (Molecular Devices).

2.12. Determination of Tregs and Intracellular Cytokine Staining. To evaluate the recruitment of $\mathrm{T}_{\text {reg }}$ induced by ASCs 
treatment, the LLN cells were cultured in plate-coated antiCD3 for 3 hours from the LLNs of OVA-induced asthmatic mice and ASC-treated asthmatic mice. The cells were stained with anti-CD25-APC $(0.2 \mathrm{mg} / \mathrm{mL})$, anti-CD4-FITC $(0.5 \mathrm{mg} / \mathrm{mL})$, and anti-Foxp3 $(0.2 \mathrm{mg} / \mathrm{mL})$ in accordance with the manufacturer's recommendations (BD Biosciences, San Jose, CA).

To stain intracellular IFN- $\gamma$ and IL-4, the LLN cells were first stained for CD4, subsequently fixed, permeabilized using Cytofix/Cytoperm Kit (BD Biosciences), and incubated with PE-cy7-conjugated anti-IFN- $\gamma$ or PE-conjugated antiIL-4. Fluorescence was measured using a FACS CantoII cytometer (BD Biosciences) equipped with Canto software (BD Biosciences).

2.13. Statistical Analysis. All experiments were repeated a minimum of three times. Data are expressed as mean \pm SEM. Statistical significance was assessed by the Student's $t$-test or ANOVA using the SPSS software package version 18.0 (SPSS Inc., Chicago, IL). A value of $P<0.05$ was considered significant.

\section{Results}

3.1. Isolation, Immunophenotypic Analysis, and Multilineage Differentiation of ASCs. The cultured ASCs from adipose tissue of C57BL/6 mice were negative for CD45, CD117, and CD11b but were positive for Sca-1, CD44, and CD90 (Figure 2(a)). These putative ASCs had a spindle shaped fibroblast-like appearance, similar to previously reported adipose tissue and bone marrow-derived MSCs (Figure 2(b)). The multilineage capacity of ASCs was demonstrated by incubating the cells in the media that promoted differentiation into the adipogenic, osteogenic, and chondrogenic lineage (Figures 2(c), 2(d), and 2(e)).

3.2. Systemic Administration of ASCs Suppresses Allergic Nasal Symptoms. To investigate whether the administration of ASCs inhibits the occurrence of nasal symptoms, clinical parameters were measured. The frequency of sneezing and nasal rubbing was significantly increased by OVA challenge. The number of nasal symptoms after the final challenge was significantly higher in the OVA group than in the PBS group $(P<0.001)$. Interestingly, ASCs treatment before the challenge phase significantly reduced the number of nasal symptoms $(P=0.023)$ (data not shown).

3.3. Systemic Administration of ASCs Reduces AHR, Lung Inflammation, and Mucus Production. To identify the effect of ASCs on lung function, AHR was measured. Penh values in four groups were increased with increasing concentrations of methacholine. Penh values in asthmatic mice at 25$50 \mathrm{mg} / \mathrm{mL}$ were significantly higher than those in the PBS and OVA+ASC group. ASCs treatment significantly decreased at different concentrations from 25 to $50 \mathrm{mg} / \mathrm{mL}$ in response to methacholine in asthmatic mice $(P=0.002$ and $P<0.001$, resp.) (Figure 3(a)).

To determine the effect of ASCs on inflammation in asthmatic mice, inflammatory cells in BALF were stained and counted. The number of total inflammatory cells and eosinophils was increased in the BALF of OVA group compared to PBS group. However, ASCs treatment significantly decreased the number of total inflammatory cells and eosinophils in asthmatic mice $(P=0.009$ and $P=0.010$, resp.) (Figure 3(b)).

No obvious infiltration of inflammatory cells was found in the PBS and PBS+ASC group, but a greater number of eosinophils around the peribronchial and perivascular area were seen in the OVA group $(P<0.001)$ (Figures 3(c) and 3(e)). Concurrently, PAS-stained goblet cell hyperplasia, as demonstrated by the increased number and size of goblet cells, also occurred within the respiratory epithelium in the OVA group $(P<0.001)$ (Figures 3(d) and 3(f)). However, this hyperplasia was not found in the airways in both the PBS group and PBS+ASC group. Interestingly, ASCs treatment induced a significant reduction in the number of eosinophils $(P=0.002)$ (Figures 3(c) and 3(e)) and goblet cell hyperplasia $(P=0.02)$ (Figures $3(\mathrm{~d})$ and $3(\mathrm{f}))$ in asthmatic mice.

3.4. Systemic Administration of ASCs Decreases IgE and IgG1. To determine whether injected ASCs affect Th2-specific immunoglobulin concentrations in the serum, the total and OVA-specific IgE, IgG1, and IgG2a levels were determined. Total and OVA-specific IgE and IgG1 levels were significantly higher in the OVA group than in the PBS group (all $P<$ 0.001). However, systemic administration of ASCs resulted in a significant decrease in total IgE and IgG1 (all $P=0.033$ ) and OVA-specific IgE and IgG1 levels $(P=0.025$ and $P=0.013$, resp.) in asthmatic mice. There were no significant differences in serum total and OVA-specific IgG2a levels in all groups (Figure 4).

3.5. Systemic Administration of ASCs Alters Cytokine Levels in Both the BALF and the LLN. To determine whether the administration of ASCs affects cytokine production, the cytokines in both the BALF and the LLN were analyzed. OVAchallenged mice showed significantly increased levels of IL-4, IL-5, and IL-13 in the BALF (all $P<0.001$ ). However, ASCs treatment resulted in a significant decrease in IL-4, IL-5, and IL-13 in the BALF $(P<0.001, P=0.020$, and $P<0.001$, resp.) and $\operatorname{LLN}(P<0.004, P=0.018$, and $P<0.001$, resp.). In contrast, higher levels of IFN- $\gamma$ were observed in both the BALF and the LLN of OVA+ASC group compared to OVA group $(P=0.001$ and $P=0.026$, resp.). Interestingly, ASC treatment significantly increased IL-10 and TGF- $\beta$ in the BALF (all $P<0.001$ ) and LLN (all $P=0.001$ ) of OVA+ASC group (Figure 5).

3.6. Systemic Administration of ASCs Enhances Tregs Expansion, Gene Expression of IDO and TGF- $\beta$, and $P G E_{2}$. To study the mechanism underlying the immunomodulatory effects of ASCs in asthmatic mice, $\mathrm{CD} 4^{+} \mathrm{CD} 25^{+}$Tregs, IL- $4^{+} \mathrm{CD} 4^{+}$ $\mathrm{T}$ cells, IFN $-\gamma^{+} \mathrm{CD} 4^{+} \mathrm{T}$ cells, and gene expression of IDO and TGF- $\beta$ were explored. The population of Tregs in LLN of asthmatic mice was markedly increased by administration of ASCs in asthmatic mice $(P=0.017)$ (Figure 6(a)). $\mathrm{IL}-4^{+} \mathrm{CD} 4^{+} \mathrm{T}$ cells in LLNs were significantly decreased 

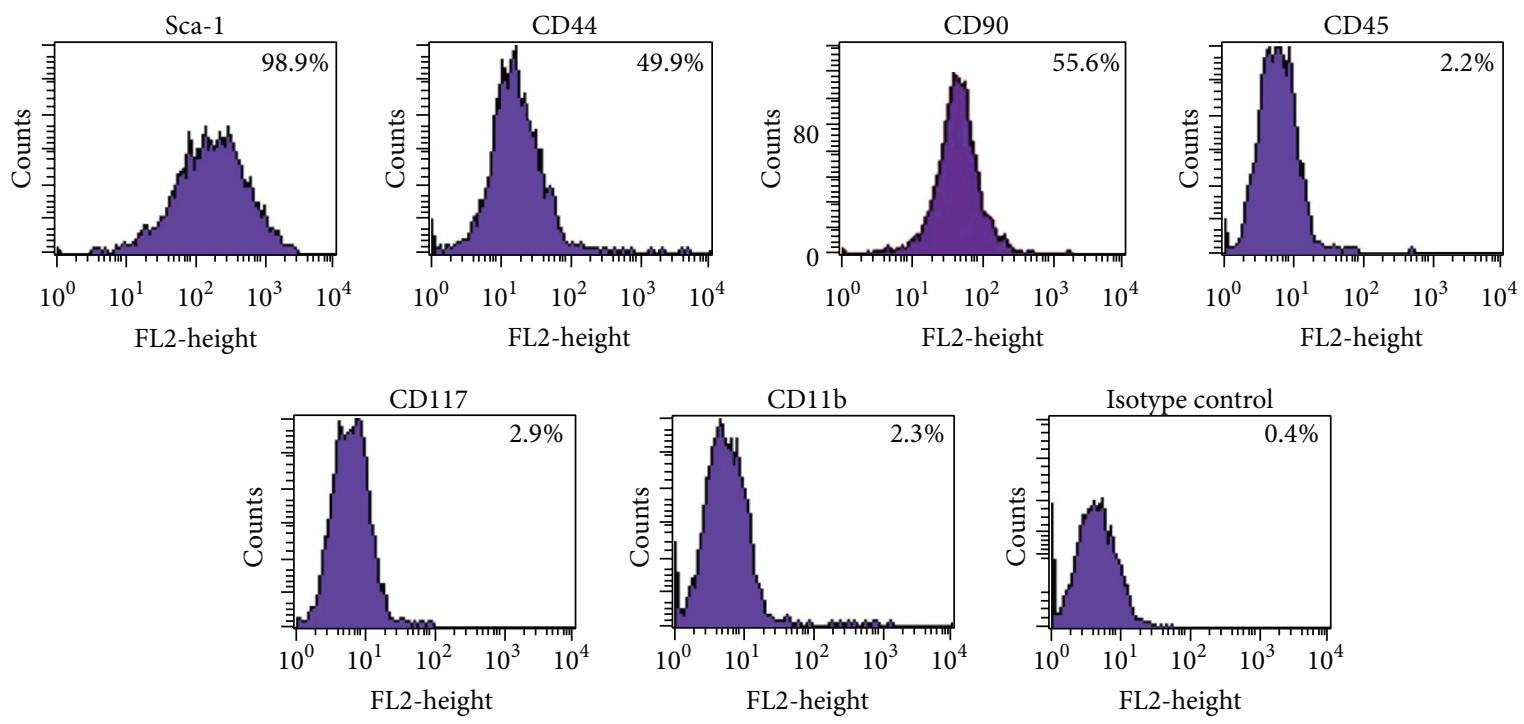

(a)

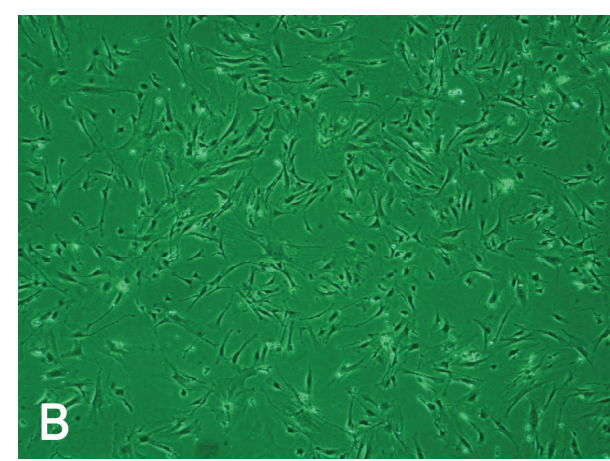

(b)

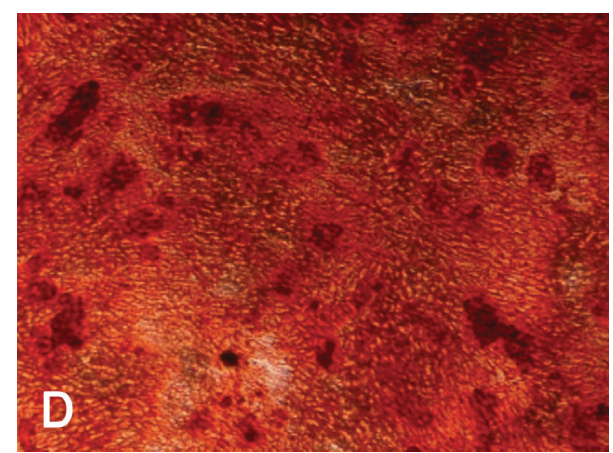

(d)

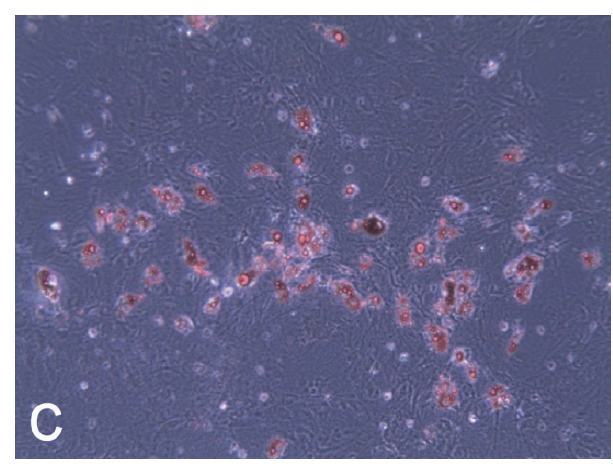

(c)

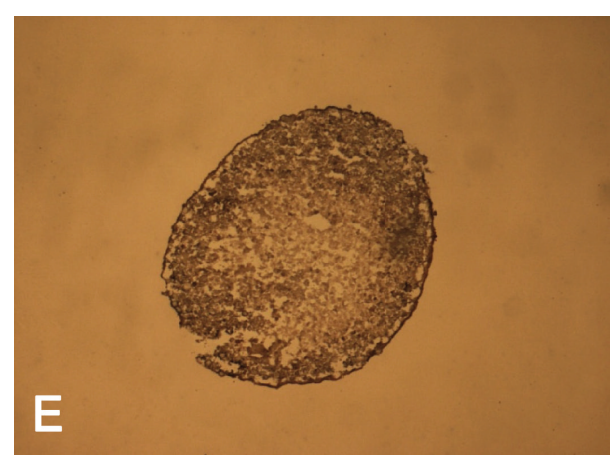

(e)

FIGURE 2: Characteristics of adipose-derived stem cells (ASCs). ASCs show characteristics of mesenchymal stem cells in the immunophenotypic analysis (a), fibroblast-like morphology (b), adipogenesis (c), osteogenesis (d), and chondrogenesis (e) (original magnification $\times 40$ ).

$(P=0.003)$ (Figure 6(b)) and IFN $-\gamma^{+} \mathrm{CD} 4^{+} \mathrm{T}$ cells in LLNs were significantly increased $(P=0.015)$ (Figure 6(c)) in the OVA+ASC group compared to the OVA group. In addition, gene expression levels of IDO and TGF- $\beta$ of lung tissue and $\mathrm{PGE}_{2}$ levels in the serum were significantly increased in the OVA+ASC group compared to the OVA group $(P=0.003, P=0.018$, and $P=0.005$, resp. $)$ (Figure 6(d)).

\section{Discussion}

The immunomodulatory function of MSCs makes them promising candidates for allergic disease therapy. MSCs isolated from the BM and adipose tissues have similar morphology, phenotype, and differentiation capability [22]. Furthermore, both BM-MSCs and ASCs have immunosuppressive properties [23]. Because of their abundance, relatively easy 


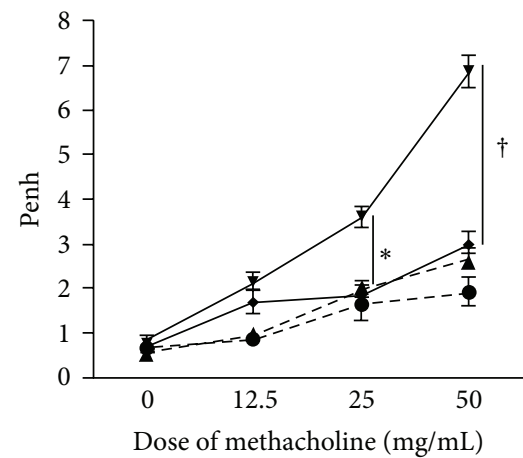

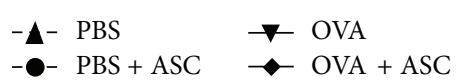

(a)

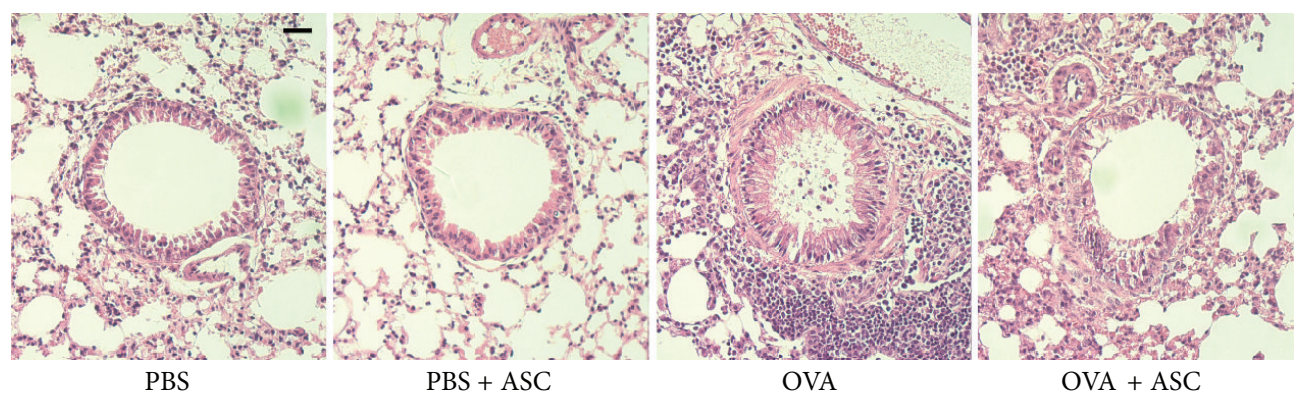

(c)

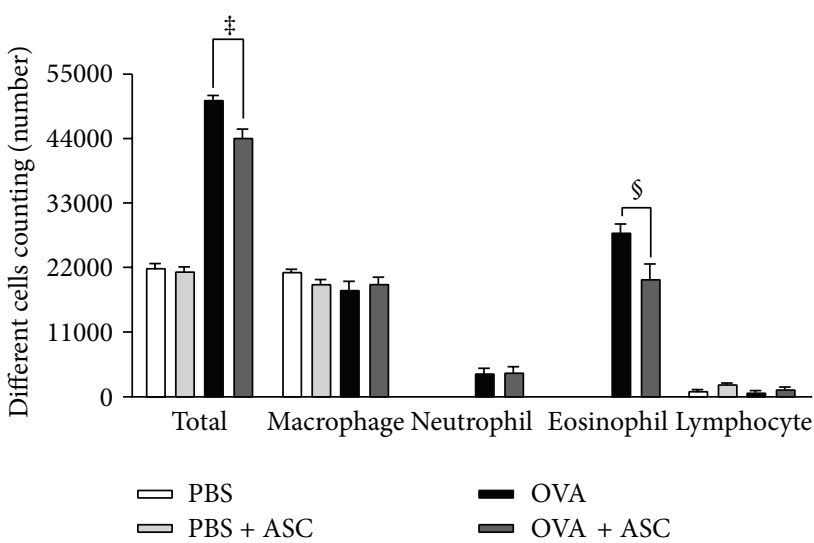

(b)

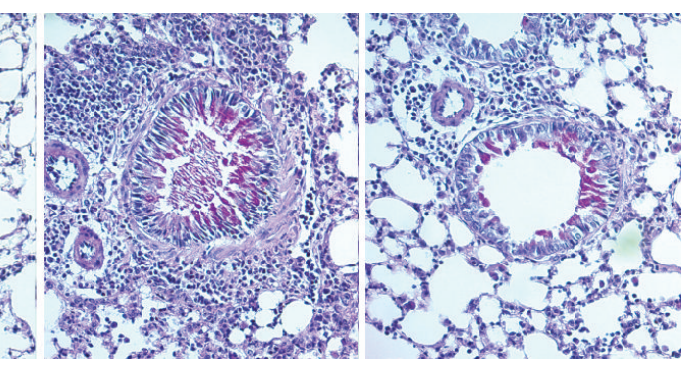

OVA

OVA + ASC

(d)

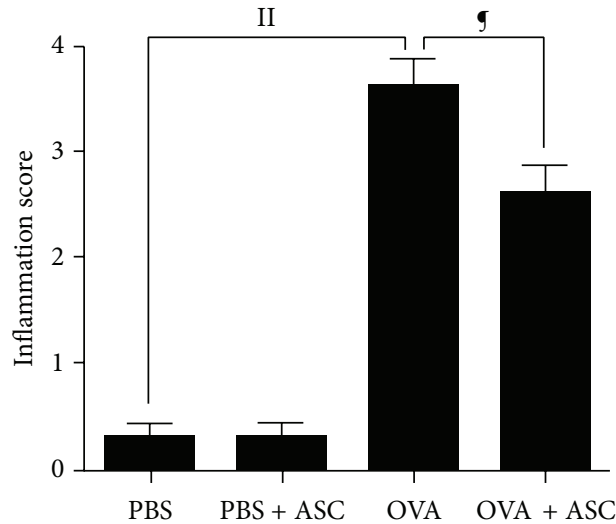

(e)

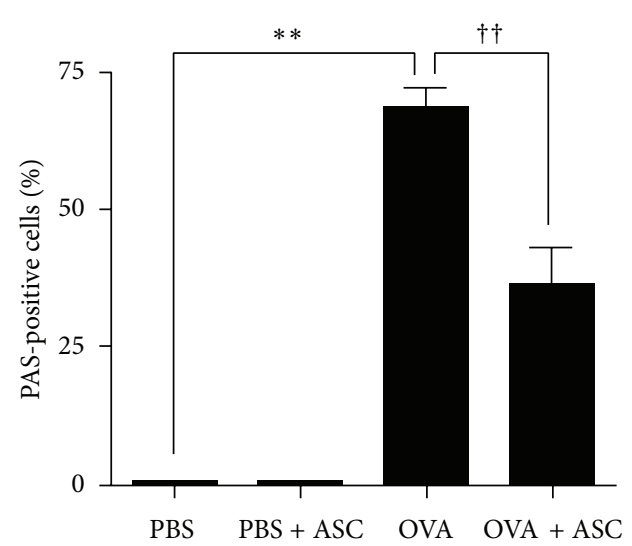

(f)

FIGURE 3: Effect of adipose-derived stem cells (ASCs) on AHR, lung inflammation, and mucus production. Airway reactivity to methacholine challenge (a) and the number of total inflammatory cells and eosinophils (b) was significantly decreased in the OVA+ASC group compared to the OVA group. (c) ASCs treatment decreased the infiltration of eosinophils ((c), (e)) and PAS-positive cells ((d), (f)) around the airway and blood vessel $(\mathrm{H} \& \mathrm{E}, \mathrm{PAS} \times 200)$. 

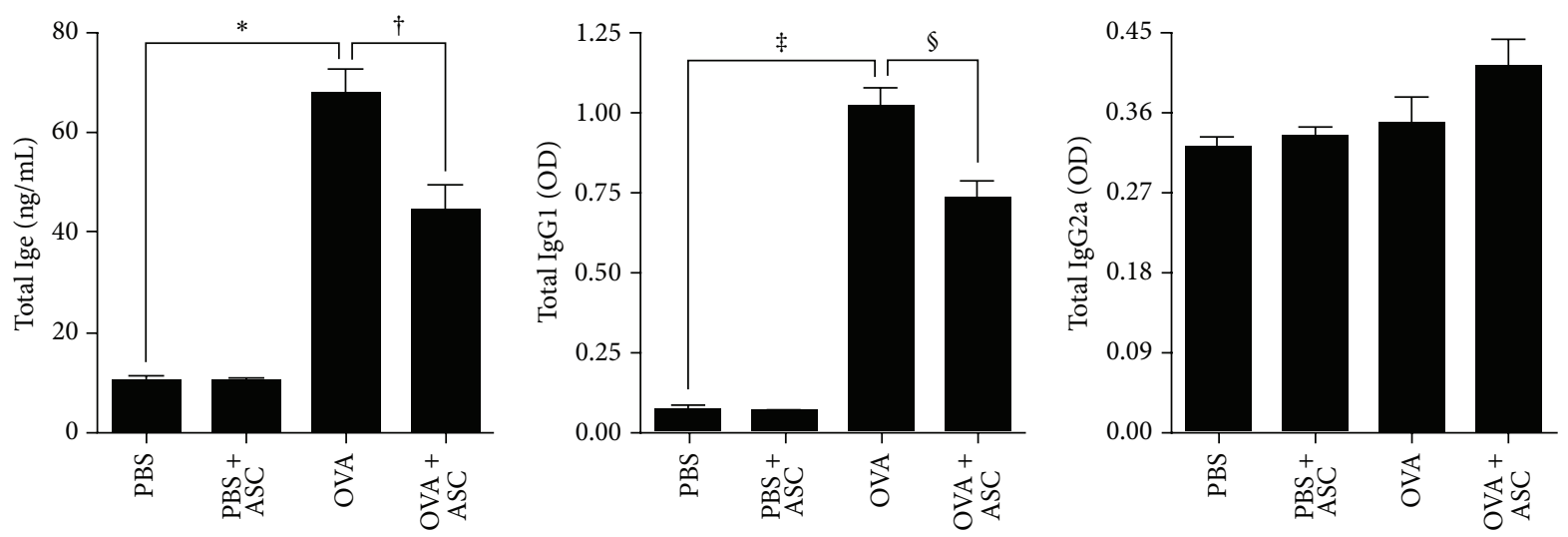

(a)
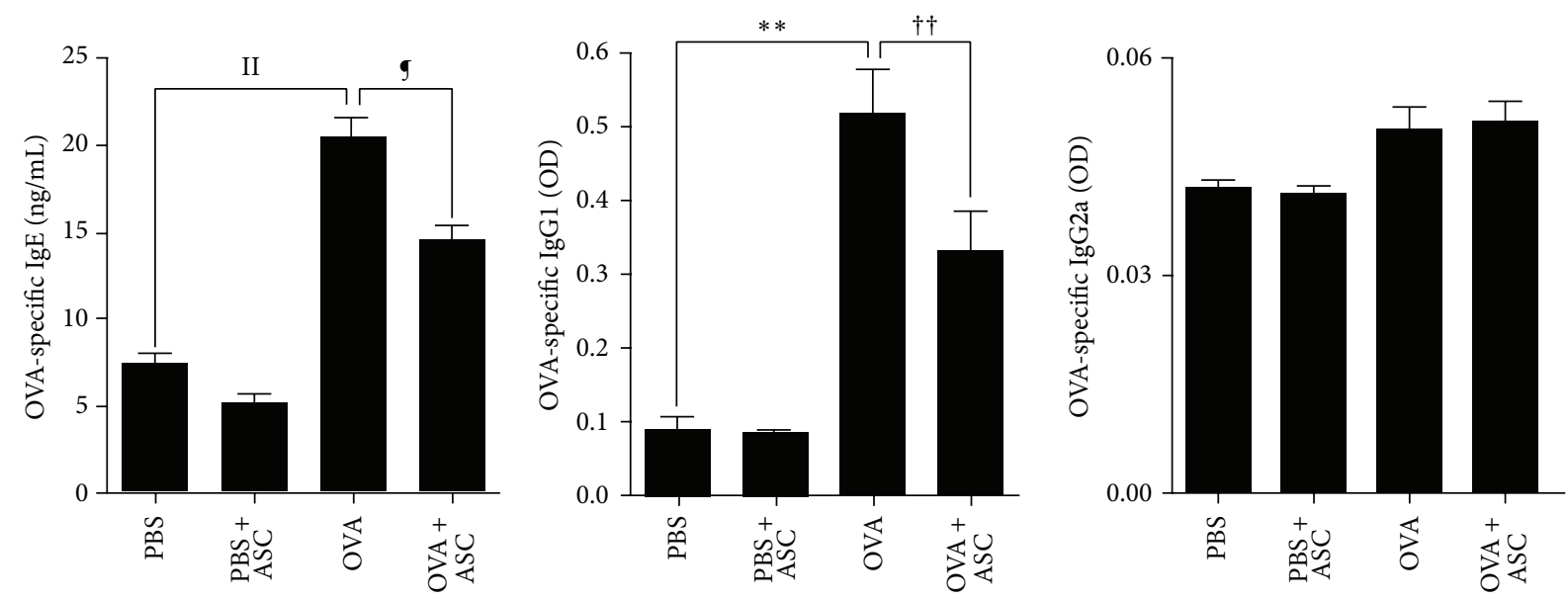

(b)

FIGURE 4: Effect of adipose-derived stem cells (ASCs) on serum levels of immunoglobulin. Total (a) and OVA-specific (b) IgE and IgG1 levels were significantly higher in the OVA group than in the PBS group. Systemic administration of ASCs resulted in a significant decrease in total (a) and OVA-specific (b) IgE and IgG1 levels in asthmatic mice.

harvesting, and high proliferation potential, ASCs might be a more useful source for cell therapy of allergic airway experimental studies [24]. Administration of MSCs can ameliorate severity of acute lung injury and fibrosis [25-27] and modulation of proinflammatory and anti-inflammatory cytokines is considered as the main beneficial effect of MSCs. Since asthma is characterized as chronic airway inflammation with eosinophilic infiltration and unbalance between Th1- and Th2-derived cytokines, we propose that ASCs-driven immunomodulation contributes to attenuation of airway inflammation in asthma, consequently improving lung function.

In this study, OVA challenge induced an infiltration of inflammatory cells in the airway and BALF as well as goblet cell hyperplasia in the airway of asthmatic mice. ASCs administration led to a significant histological and functional improvement in asthmatic mice. ASCs significantly decreased total cell number and eosinophils in BALF and improved lung pathology such as lung inflammation scores and goblet cell hyperplasia. These findings indicate that ASCs inhibited recruitment of eosinophils and mononuclear cells into the airway and BALF and reduced AR symptoms and AHR in asthmatic mice, which is consistent with previous studies $[11,12,15,17]$. However the mechanisms underlying the beneficial effect of ASCs in allergic airway diseases are unclear.

As expected, ASCs administrations significantly decreased total and OVA-specific IgE and IgG1 serum levels. The levels of Th2 cytokines (IL-4, IL-5, and IL-13) were significantly decreased after the administration of ASCs, whereas IFN $-\gamma$ and regulatory cytokines (IL-10 and TGF$\beta$ ) were significantly increased in the BALF and LLN. We also demonstrated that the ratio of Tregs in ASCs-treated asthmatic mice was significantly higher than in untreated mice, which was similar to previous studies that indicate that BM-MSCs preferentially activate CD4+CD25+ T cell subsets, which are the main underlying mechanisms for immunosuppressive activity of MSCs $[8,28]$. BM-MSCs prevented the occurrence of severe, irreversible damage to bone and cartilage in murine rheumatoid arthritis model by inducing production of antigen-specific Tregs [29]. However, the effect of MSCs on Tregs in allergic airway diseases is still unknown. 

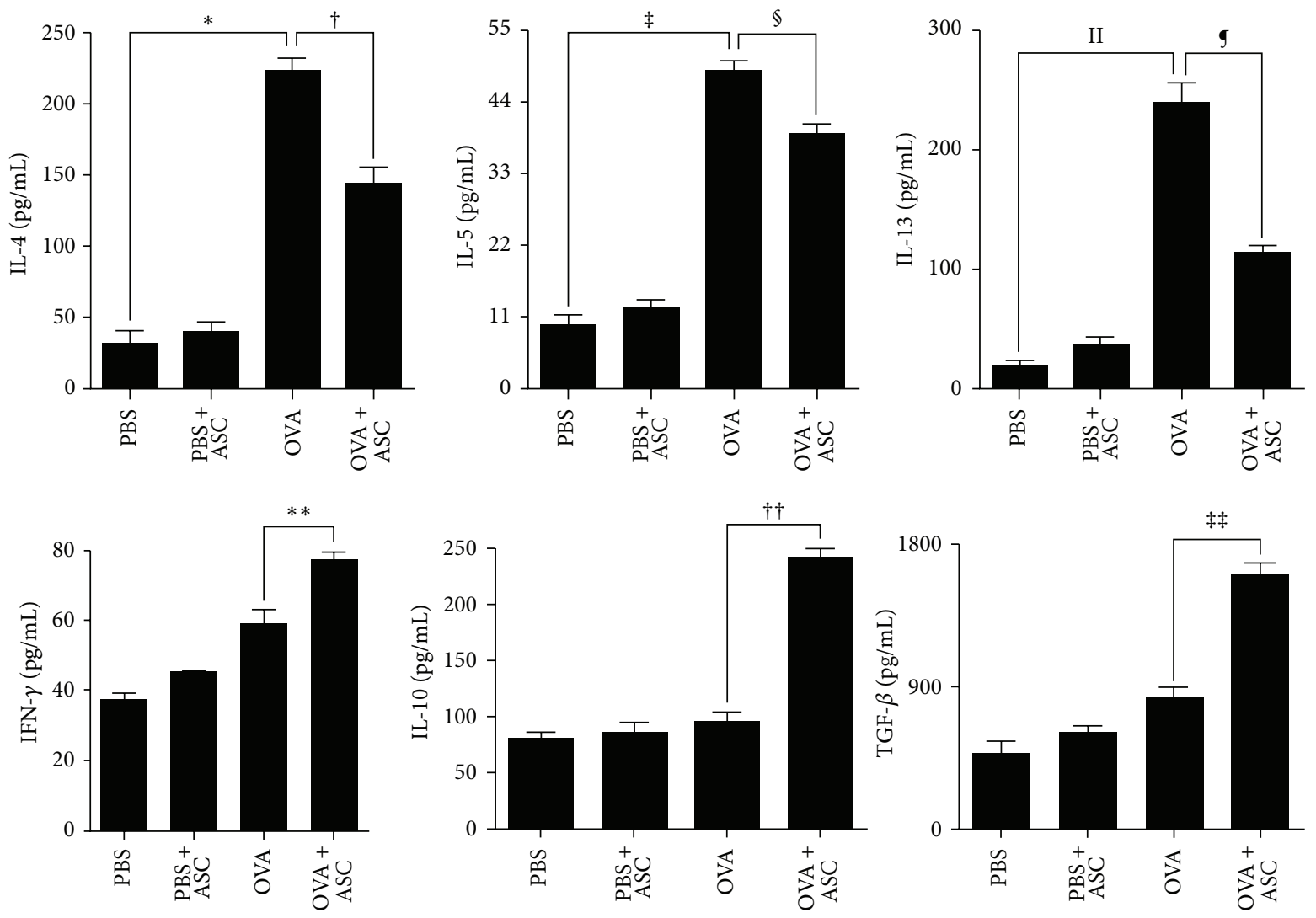

(a)
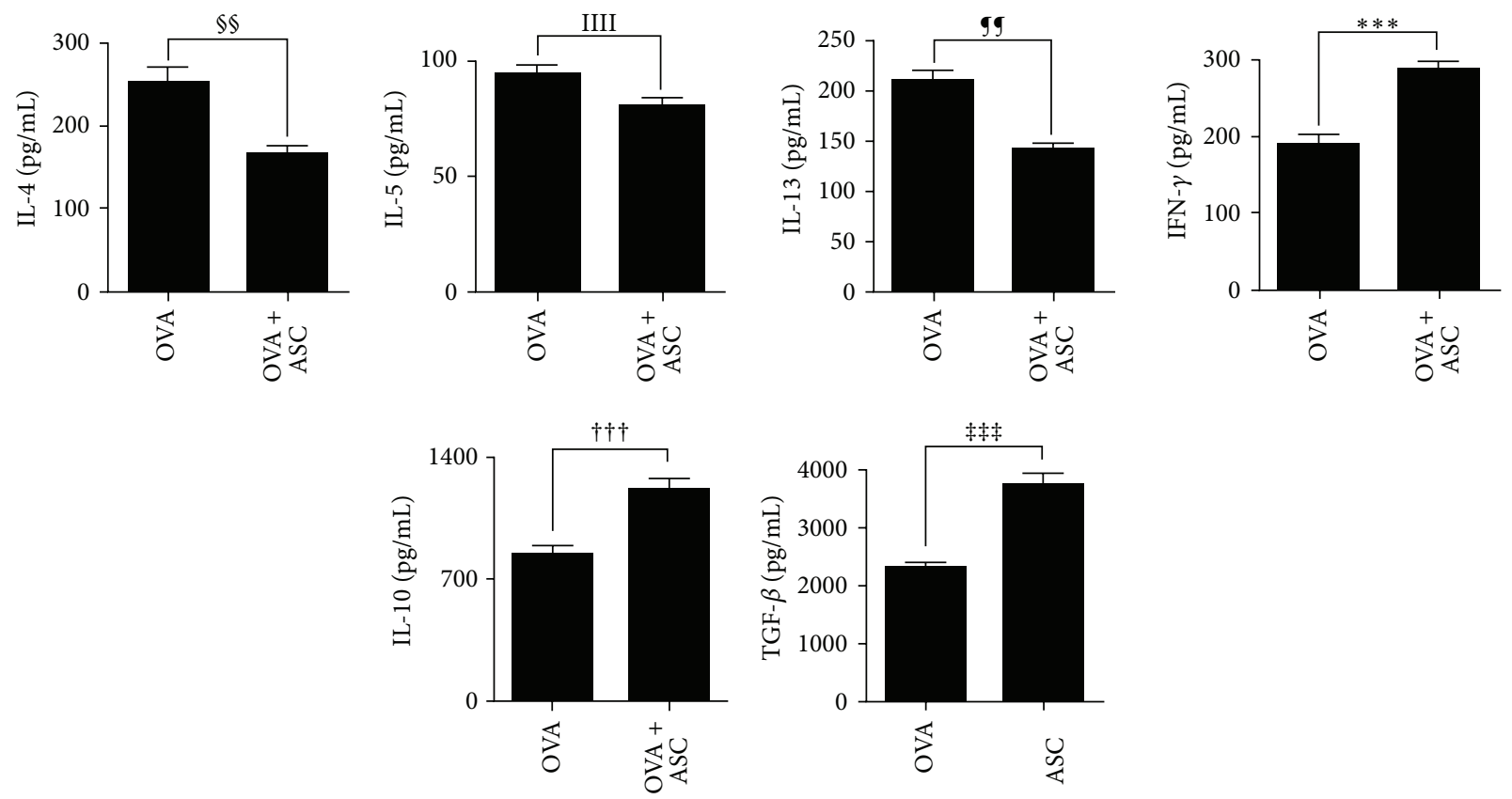

(b)

FIGURE 5: Effect of adipose-derived stem cells (ASCs) on cytokine levels of BALF (a) and LLNs (b). IL-4, IL-5, and IL-13 levels were significantly higher in the BALF of the OVA group than PBS group. ASCs treatment significantly decreased the levels of IL-4, IL-5, and IL-13 in the BALF and LLNs but increased the levels of IFN- $\gamma$, IL-10, and TGF- $\beta$ in the BALF and LLNs. 

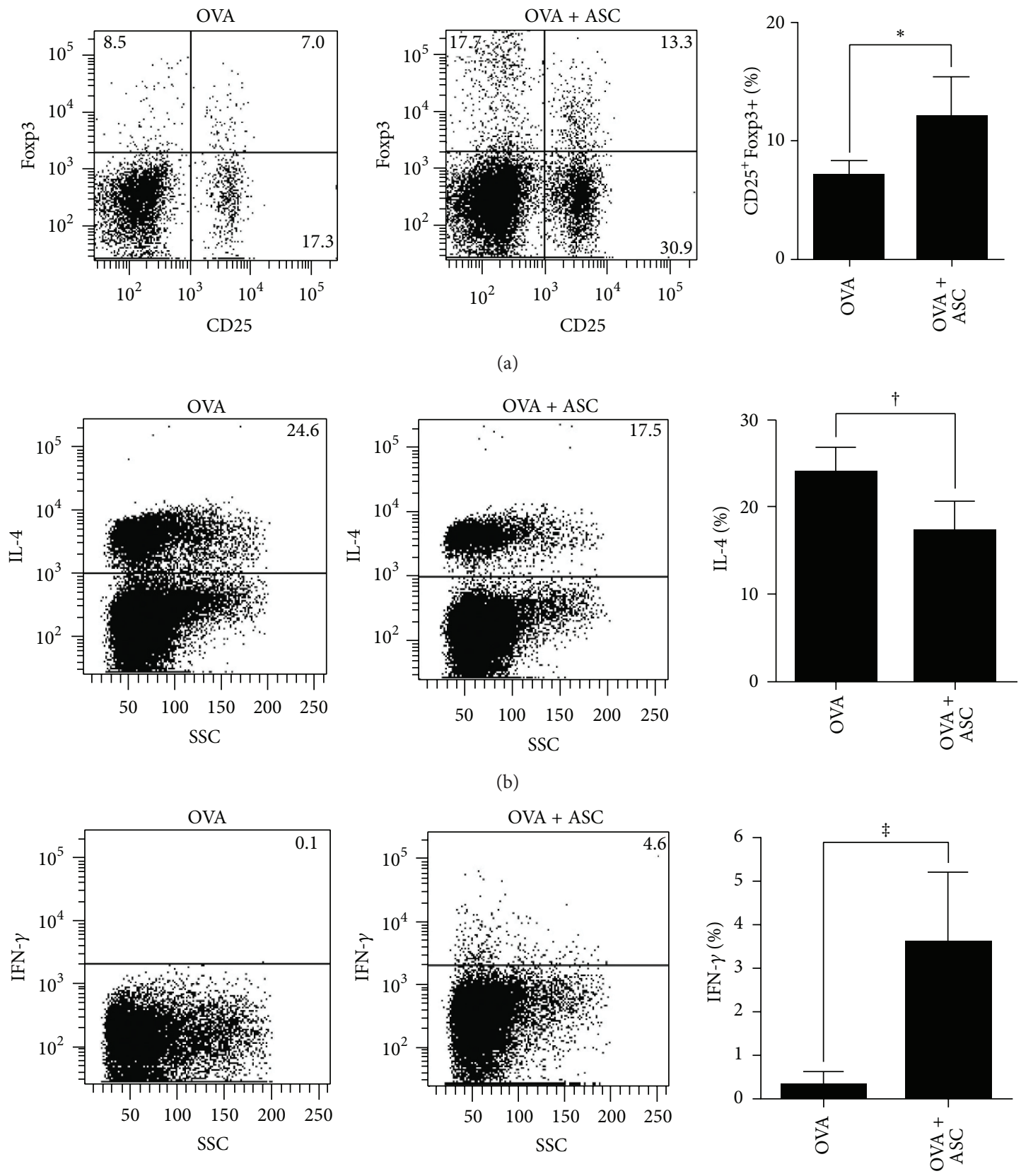

(c)
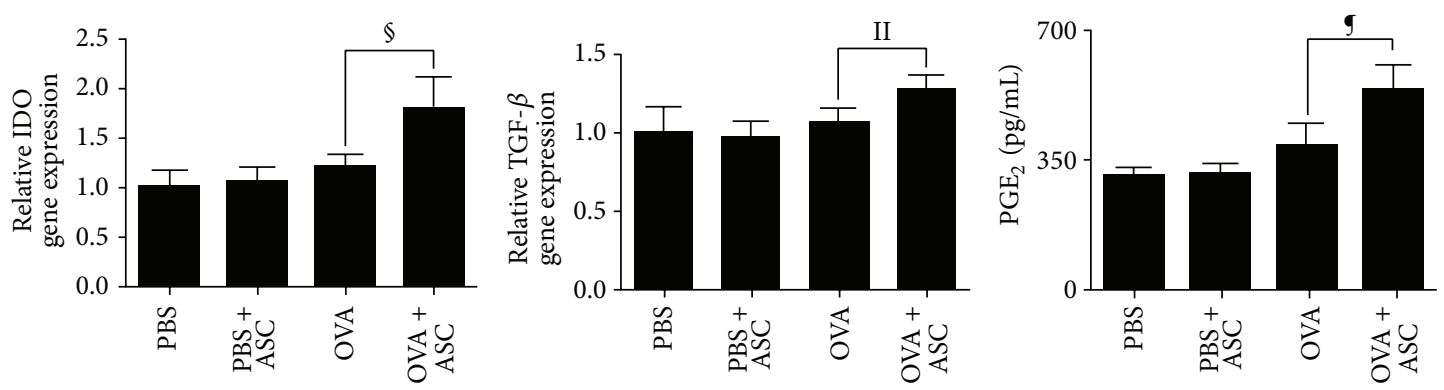

(d)

FIGURE 6: Effects of adipose-derived stem cells (ASCs) on Tregs, IL-4 or IFN- $\gamma$ producing T cells, and gene expression of IDO and TGF- $\beta$. (a) ASCs treatment significantly increased the frequency of Tregs. IL $-4^{+} \mathrm{CD} 4^{+} \mathrm{T}$ cells (b) were significantly decreased, but IFN- $\gamma^{+} \mathrm{CD} 4^{+} \mathrm{T}$ cells (c) were significantly increased by ASCs treatment. (d) The gene expression levels of IDO and TGF- $\beta$ and PGE 2 levels were significantly increased by ASCs treatment. 


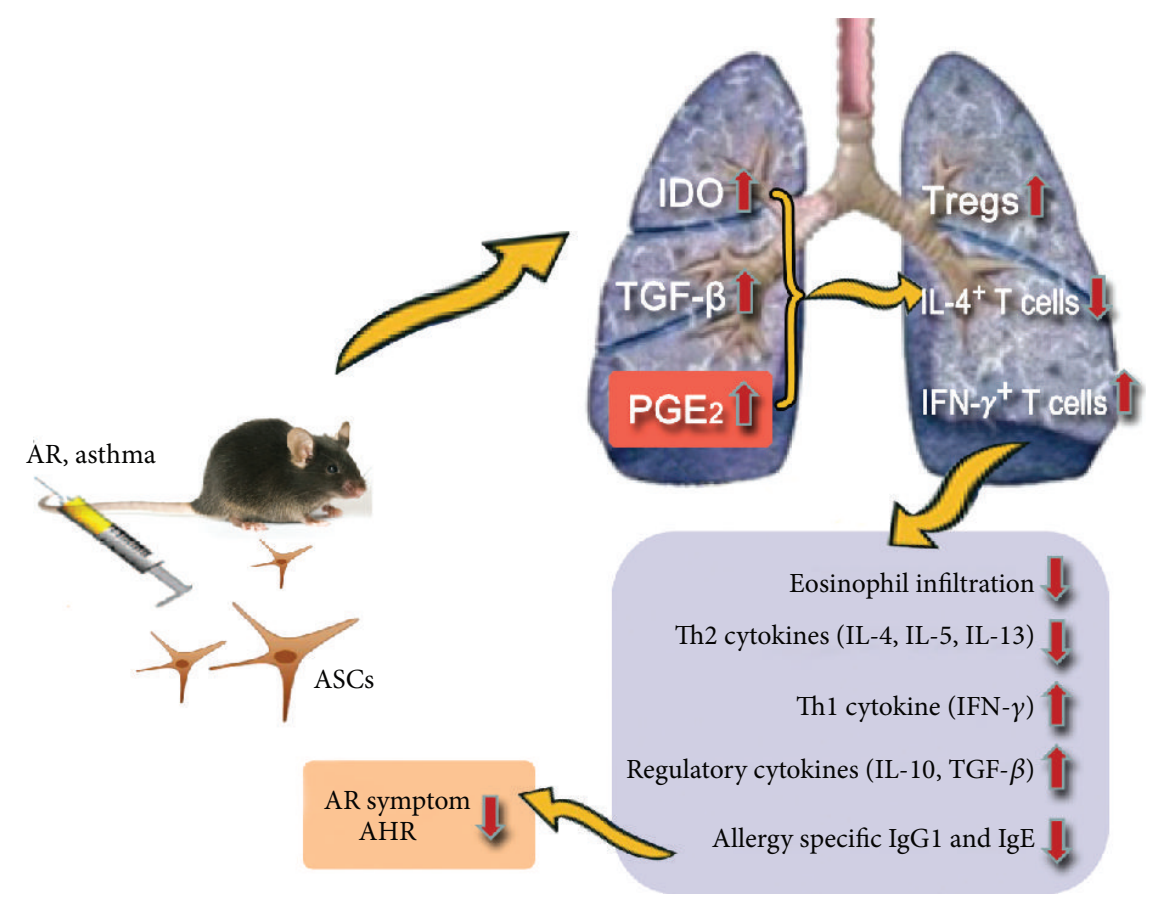

FIGURE 7: Schematic presentation of plausible mechanisms by which ASCs regulate the allergic airway diseases. ASCs migrated to the lung by intravenous administration secrete a variety of soluble factors including IDO, TGF- $\beta$, and $\mathrm{PGE}_{2}$. Through a soluble factor or direct contact of ASCs with T lymphocytes, ASCs initiate the expansion of Tregs. Tregs secrete IL-10 and TGF- $\beta$ which ultimately lead to decrease of lung eosinophil infiltration, as well as allergy-specific Th2 cytokines and Ig production.

Our study showed that ASCs administration significantly increased the ratio of Tregs in the LLNs of asthmatic mice. Furthermore, $\mathrm{IL}-4^{+} \mathrm{CD} 4^{+} \mathrm{T}$ cells were significantly reduced after ASCs treatment, whereas IFN $-\gamma^{+} \mathrm{CD} 4^{+} \mathrm{T}$ cells were significantly increased in the LLNs. Our findings, and those from other reports, provide evidence that Treg expansion plays a central role in the immunomodulatory properties of ASCs.

Tregs are a unique T cell population with strong immunosuppressive properties. $\mathrm{CD} 4^{+} \mathrm{CD} 25^{+}$Tregs are impaired quantitatively and functionally and also play a protective role in suppressing airway eosinophilic inflammation and the development of airway hyperreactivity in asthma [30]. The induction of Tregs by MSCs involves not only direct contact between MSCs and CD $4^{+} \mathrm{T}$ cells, but also the secretion of soluble factors such as IDO, TGF- $\beta$, and PGE 2 [31]. Treatment with IFN- $\gamma$ causes MSCs to express the protein IDO and exhibit functional activity of IDO, which in turn degrades essential tryptophan and results in kynurenine synthesis and thereby suppresses lymphocyte proliferation [32]. Neutralizing antibodies against TGF- $\beta$ and BM-MSCs derived from TGF- $\beta 1-\mathrm{KO}$ mice eliminated the beneficial effect of MSCs, suggesting that the BM-MSCs-derived TGF$\beta$ is critical in suppressing the allergic responses [33, 34]. Coculturing T cells with MSCs resulted in elevated levels of $\mathrm{PGE}_{2}$, and treatment with inhibitors of $\mathrm{PGE}_{2}$ production mitigated the MSCs-mediated immune modulation [35, 36]. In this study, we observed that ASCs significantly increased IDO and TGF- $\beta$ expression in lung tissue and $\mathrm{PGE}_{2}$ levels in the serum of OVA-sensitized mice, suggesting that IDO, TGF- $\beta$, and $\mathrm{PGE}_{2}$ might be the major soluble factors responsible for Treg expansion in LLNs.

Our previous studies demonstrated that lungs are the primary site of ASCs accumulations following intravenous administration and developing allergic environment is capable of attracting and retaining more ASCs than unaffected lungs $[11,15]$. Although it remains unclear whether systemic administration of ASCs became activated by which signaling mechanism, we present the supposed schematic drawing for the mechanism of ASCs effect on the basis of previous studies $[11,15,32-36]$ and data of this study. ASCs migrated to the lung by intravenous administration secrete a variety of soluble factors including IDO, TGF- $\beta$, and $\mathrm{PGE}_{2}$. Through a soluble factor or direct contact of ASCs with T lymphocytes, ASCs induce the expansion of Tregs. Tregs secrete antiinflammatory cytokines (IL-10, TGF- $\beta$ ), which ultimately lead to decrease of lung eosinophil infiltration, as well as allergy-specific Th2 cytokines and Ig production (Figure 7).

The present study demonstrates that intravenous treatment with ASCs in asthmatic mice provides a significant reduction of allergic airway inflammation and improvement of lung function. These immunomodulatory effects might be mediated by upregulating Tregs and partly involve increasing soluble factors such as IDO, TGF- $\beta$, and $\mathrm{PGE}_{2}$.

\section{Conflict of Interests}

The authors have no funding, financial relationships, or conflict of interests to disclose. 


\section{Authors' Contribution}

Kyu-Sup Cho and Mi-Kyung Park contributed equally to the content of this paper. Kyu-Sup Cho was responsible for drafting the paper, acquisition of data, analysis, and interpretation of data. Mi-Kyung Park was responsible for drafting the paper, acquisition of data, analysis, and interpretation of data. Shin-Ae Kang was responsible for acquisition of data. HeeYoung Park was responsible for acquisition of data. SungLyong Hong was responsible for analysis and interpretation of data. Hye-Kyung Park was responsible for analysis and interpretation of data. Hak-Sun Yu was responsible for analysis and interpretation of data, conception, and design. Hwan-Jung Roh was responsible for conception and design.

\section{Acknowledgment}

This study was supported by a grant of the Korean Health Technology R\&D Project, Ministry of Health \& Welfare, Republic of Korea (HI12C0315).

\section{References}

[1] J. Bousquet, N. Khaltaev, A. A. Cruz et al., "Allergic Rhinitis and its Impact on Asthma (ARIA) 2008 update (in collaboration with the World Health Organization, GA2LEN and AllerGen)," Allergy, vol. 63, no. 86, pp. 8-160, 2008.

[2] L. Cohn, J. A. Elias, and G. L. Chupp, "Asthma: mechanisms of disease persistence and progression," Annual Review of Immunology, vol. 22, pp. 789-815, 2004.

[3] M. S. Wilson, M. D. Taylor, A. Balic, C. A. M. Finney, J. R. Lamb, and R. M. Maizels, "Suppression of allergic airway inflammation by helminth-induced regulatory T cells," Journal of Experimental Medicine, vol. 202, no. 9, pp. 1199-1212, 2005.

[4] K. S. Cho, H. Y. Park, H. J. Roh, D. T. Bravo, P. H. Hwang, and J. V. Nayak, "Human ethmoid sinus mucosa: a promising novel tissue source of mesenchymal progenitor cells," Stem Cell Research \& Therapy, vol. 5, article 15, 2014.

[5] R. S. Tuan, G. Boland, and R. Tuli, "Adult mesenchymal stem cells and cell-based tissue engineering," Arthritis Research and Therapy, vol. 5, no. 1, pp. 32-45, 2003.

[6] H. Klingemann, D. Matzilevich, and J. Marchand, "Mesenchymal stem cells-sources and clinical applications," Transfusion Medicine and Hemotherapy, vol. 35, no. 4, pp. 272-277, 2008.

[7] A. Uccelli, L. Moretta, and V. Pistoia, "Immunoregulatory function of mesenchymal stem cells," European Journal of Immunology, vol. 36, no. 10, pp. 2566-2573, 2006.

[8] Z. Selmani, A. Naji, I. Zidi et al., "Human leukocyte antigenG5 secretion by human mesenchymal stem cells is required to suppress T lymphocyte and natural killer function and to induce CD4+ CD25highFOXP3+ regulatory T cells," Stem Cells, vol. 26, no. 1, pp. 212-222, 2008.

[9] G. M. Spaggiari, A. Capobianco, H. Abdelrazik, F. Becchetti, M. C. Mingari, and L. Moretta, "Mesenchymal stem cells inhibit natural killer-cell proliferation, cytotoxicity, and cytokine production: role of indoleamine 2,3-dioxygenase and prostaglandin E2," Blood, vol. 111, no. 3, pp. 1327-1333, 2008.

[10] K. English, F. P. Barry, and B. P. Mahon, "Murine mesenchymal stem cells suppress dendritic cell migration, maturation and antigen presentation," Immunology Letters, vol. 115, no. 1, pp. 50$58,2008$.
[11] H. K. Park, K. S. Cho, D. H. Shin et al., "Adipose-derived stromal cells inhibit allergic airway inflammation in mice," Stem Cells and Development, vol. 19, no. 11, pp. 1811-1818, 2010.

[12] M. Goodwin, V. Sueblinvong, P. Eisenhauer et al., "Bone marrow-derived mesenchymal stromal cells inhibit Th2-mediated allergic airways inflammation in mice," Stem Cells, vol. 29, no. 7, pp. 1137-1148, 2011.

[13] T. L. Bonfield, M. Koloze, D. P. Lennon, B. Zuchowski, S. E. Yang, and A. I. Caplan, "Human mesenchymal stem cells suppress chronic airway inflammation in the murine ovalbumin asthma model," The American Journal of Physiology-Lung Cellular and Molecular Physiology, vol. 299, no. 6, pp. L760L770, 2010.

[14] Q. L. Fu, Y. Y. Chow, S. J. Sun et al., "Mesenchymal stem cells derived from human induced pluripotent stem cells modulate T-cell phenotypes in allergic rhinitis," Allergy, vol. 67, no. 10, pp. 1215-1222, 2012.

[15] K.-S. Cho, H.-K. Park, H.-Y. Park et al., "IFATS collection: immunomodulatory effects of adipose tissue-derived stem cells in an allergic rhinitis mouse model," Stem Cells, vol. 27, no. 1, pp. 259-265, 2009.

[16] Y. Q. Sun, M. X. Deng, J. He et al., "Human pluripotent stem cell-derived mesenchymal stem cells prevent allergic airway inflammation in mice," Stem Cells, vol. 30, no. 12, pp. 2692-2699, 2012.

[17] K. Cho and H. Roh, "Immunomodulatory effects of adiposederived stem cells in airway allergic diseases," Current Stem Cell Research and Therapy, vol. 5, no. 2, pp. 111-115, 2010.

[18] C. Pellaton-Longaretti, C. Boudousquié, N. Barbier et al., "CD $4^{+} \mathrm{CD} 25-\mathrm{mTGF} \beta^{+} \mathrm{T}$ cells induced by nasal application of ovalbumin transfer tolerance in a therapeutic model of asthma," International Immunology, vol. 23, no. 1, pp. 17-27, 2011.

[19] C. G. Lee, H. Link, P. Baluk et al., "Vascular endothelial growth factor (VEGF) induces remodeling and enhances $\mathrm{T}_{H} 2$ mediated sensitization and inflammation in the lung," Nature Medicine, vol. 10, no. 10, pp. 1095-1103, 2004.

[20] K. G. Tournoy, J. C. Kips, C. Schou, and R. A. Pauwels, "Airway eosinophilia is not a requirement for allergen-induced airway hyperresponsiveness," Clinical and Experimental Allergy, vol. 30, no. 1, pp. 79-85, 2000.

[21] H. K. Jin, S. K. Byung, G. U. Tae et al., “ $\gamma$-secretase inhibitor reduces allergic pulmonary inflammation by modulating $\mathrm{Th} 1$ and Th2 responses," The American Journal of Respiratory and Critical Care Medicine, vol. 179, no. 10, pp. 875-882, 2009.

[22] R. H. Lee, B. Kim, I. Choi et al., "Characterization and expression analysis of mesenchymal stem cells from human bone marrow and adipose tissue," Cellular Physiology and Biochemistry, vol. 14, no. 4-6, pp. 311-324, 2004.

[23] B. Puissant, C. Barreau, P. Bourin et al., "Immunomodulatory effect of human adipose tissue-derived adult stem cells: comparison with bone marrow mesenchymal stem cells," British Journal of Haematology, vol. 129, no. 1, pp. 118-129, 2005.

[24] H. Jang, K. Cho, H. Park, and H. Roh, "Adipose tissue-derived stem cells for cell therapy of airway allergic diseases in mouse," Acta Histochemica, vol. 113, no. 5, pp. 501-507, 2011.

[25] V. Sueblinvong and D. J. Weiss, "Stem cells and cell therapy approaches in lung biology and diseases," Translational Research, vol. 156, no. 3, pp. 188-205, 2010.

[26] G. Wang, B. A. Bunnell, R. G. Painter et al., "Adult stem cells from bone marrow stroma differentiate into airway epithelial cells: potential therapy for cystic fibrosis," Proceedings of the 
National Academy of Sciences of the United States of America, vol. 102, no. 1, pp. 186-191, 2005.

[27] M. Mao, S. N. Wang, X. J. Lv, Y. Wang, and J. C. Xu, "Intravenous delivery of bone marrow-derived endothelial progenitor cells improves survival and attenuates lipopolysaccharide-induced lung injury in rats," Shock, vol. 34, no. 2, pp. 196-204, 2010.

[28] R. Maccario, M. Podestà, A. Moretta et al., "Interaction of human mesenchymal stem cells with cells involved in alloantigen-specific immune response favors the differentiation of $\mathrm{CD}^{+} \mathrm{T}$-cell subsets expressing a regulatory/suppressive phenotype," Haematologica, vol. 90, no. 4, pp. 516-525, 2005.

[29] A. Augello, R. Tasso, S. M. Negrini, R. Cancedda, and G. Pennesi, "Cell therapy using allogeneic bone marrow mesenchymal stem cells prevents tissue damage in collagen-induced arthritis," Arthritis \& Rheumatism, vol. 56, no. 4, pp. 1175-1186, 2007.

[30] D. Hartl, B. Koller, A. T. Mehlhorn et al., "Quantitative and functional impairment of pulmonary $\mathrm{CD} 4{ }^{+} \mathrm{CD} 25^{\text {hi }}$ regulatory $\mathrm{T}$ cells in pediatric asthma," Journal of Allergy and Clinical Immunology, vol. 119, no. 5, pp. 1258-1266, 2007.

[31] K. English, J. M. Ryan, L. Tobin, M. J. Murphy, F. P. Barry, and B. P. Mahon, "Cell contact, prostaglandin E2 and transforming growth factor beta 1 play non-redundant roles in human mesenchymal stem cell induction of CD4+CD25Highforkhead box P3+ regulatory T cells," Clinical and Experimental Immunology, vol. 156, no. 1, pp. 149-160, 2009.

[32] R. Meisel, A. Zibert, M. Laryea, U. Göbel, W. Däubener, and D. Dilloo, "Human bone marrow stromal cells inhibit allogeneic T-cell responses by indoleamine 2,3-dioxygenasemediated tryptophan degradation," Blood, vol. 103, no. 12, pp. 4619-4621, 2004.

[33] K. Nemeth, A. Keane-Myers, J. M. Brown et al., "Bone marrow stromal cells use TGF- $\beta$ to suppress allergic responses in a mouse model of ragweed-induced asthma," Proceedings of the National Academy of Sciences of the United States of America, vol. 107, no. 12, pp. 5652-5657, 2010.

[34] M. D. Nicola, C. Carlo-Stella, M. Magni et al., "Human bone marrow stromal cells suppress T-lymphocyte proliferation induced by cellular or nonspecific mitogenic stimuli," Blood, vol. 99, no. 10, pp. 3838-3843, 2002.

[35] S. Aggarwal and M. F. Pittenger, "Human mesenchymal stem cells modulate allogeneic immune cell responses," Blood, vol. 105, no. 4, pp. 1815-1822, 2005.

[36] L. Cui, Y. Shuo, W. Liu, N. Li, W. Zhang, and Y. Cao, "Expanded adipose-derived stem cells suppress mixed lymphocyte reaction by secretion of prostaglandin E2," Tissue Engineering, vol. 13, no. 6, pp. 1185-1195, 2007. 


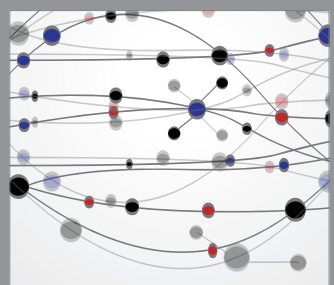

The Scientific World Journal
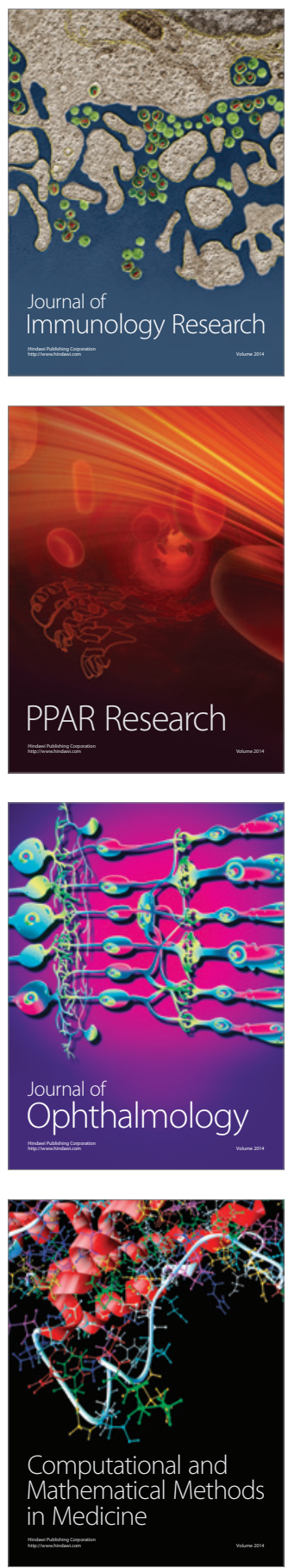

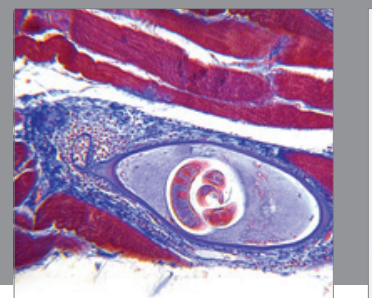

Gastroenterology

Research and Practice
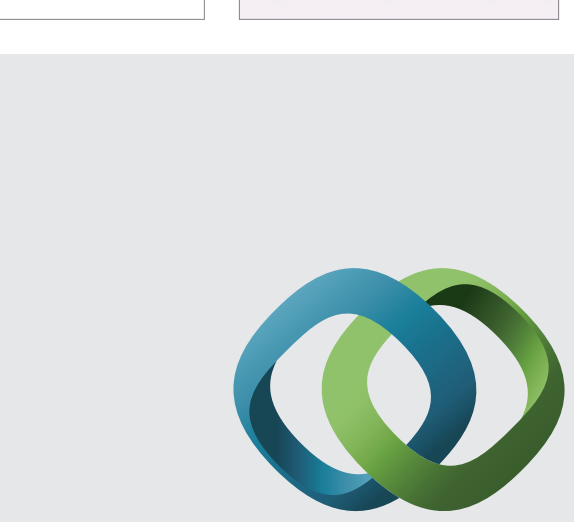

\section{Hindawi}

Submit your manuscripts at

http://www.hindawi.com
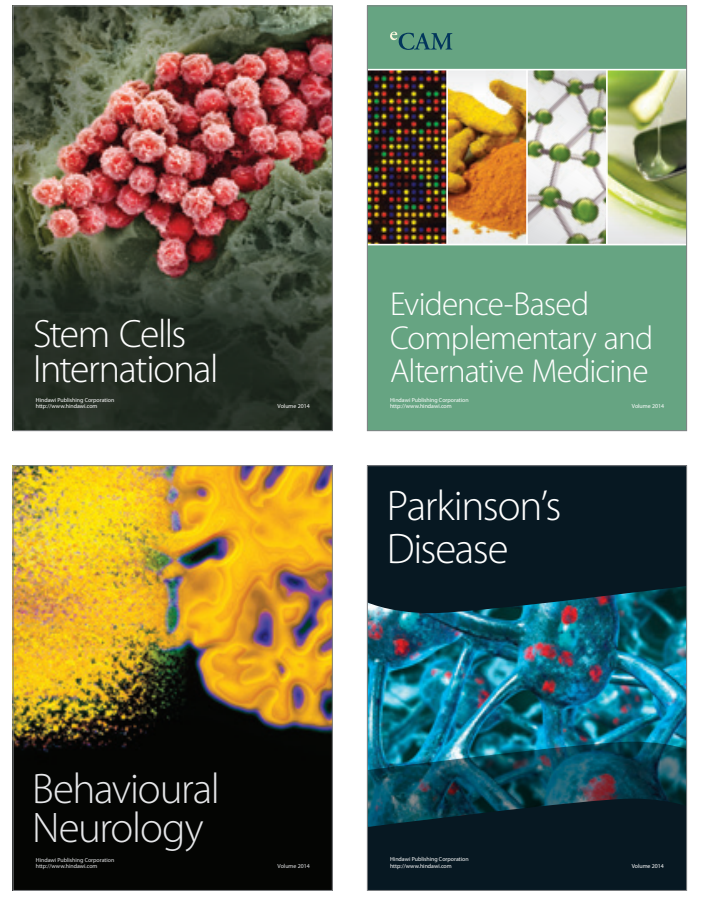
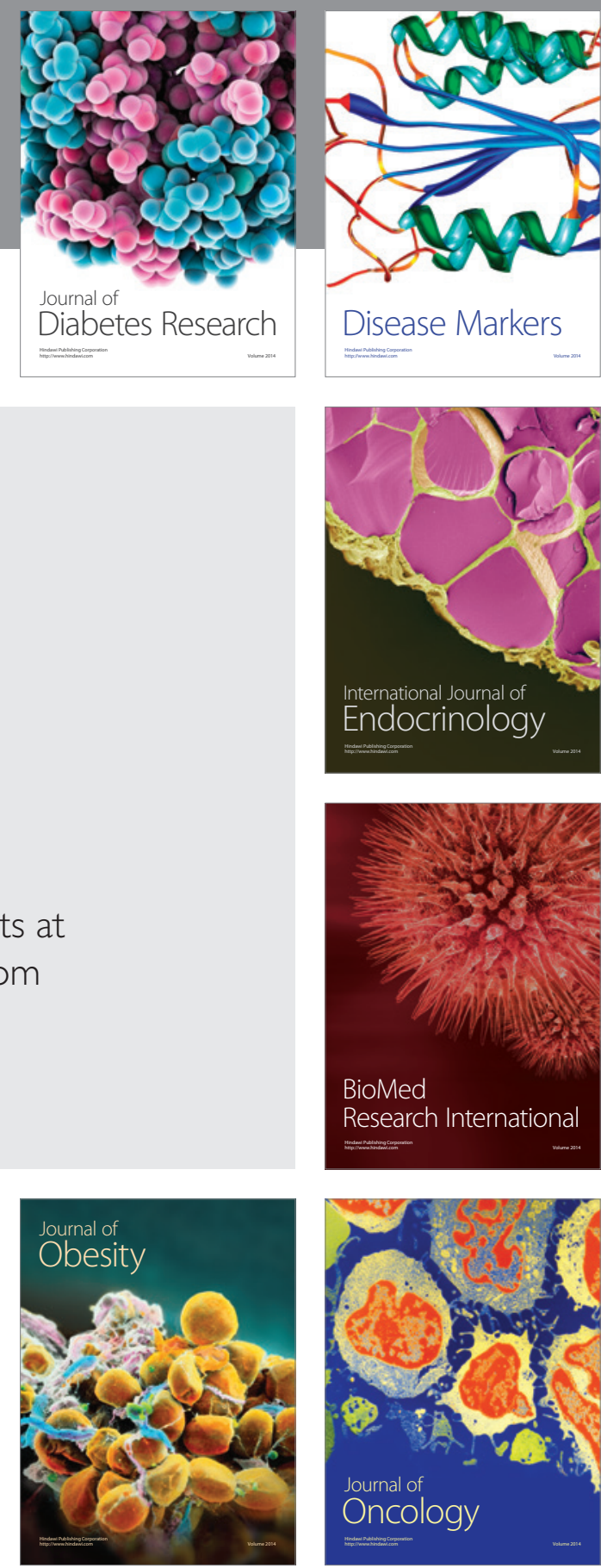

Disease Markers
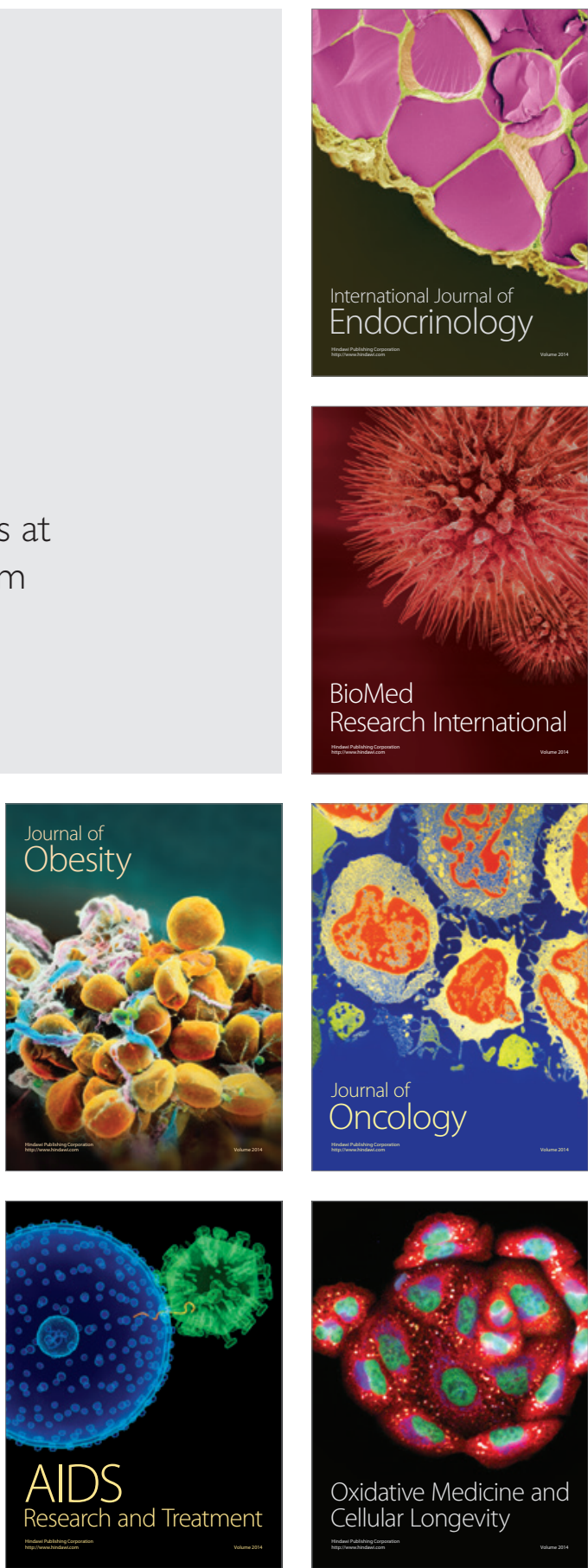